\title{
A Study on Knowledge, Attitude and Practice of rabies among residents in Addis Ababa, Ethiopia
}

\author{
${ }^{1}$ *Abraham Ali, ${ }^{2}$ Eshetu Yimer Ahmed and ${ }^{1}$ Desalegn Sifer \\ ${ }^{1}$ Ethiopian Health and Nutrition Research Institute \\ ${ }^{2}$ Development Consultant, P.O. Box 181689, Addis Ababa, Ethiopia, \\ *Corresponding author: E-mail abraalimo@yahoo.com/abrahama@ehnri.gov.et \\ Ethiopian Health and Nutrition Research Institute, P. O. Box 1242, Addis Ababa/Ethiopia, \\ Telephone: +251-112781500; +251-911861774; Fax: +251-112789121
}

\section{Abstract}

This study was conducted in Addis Ababa during the months of January and February, 2011 to assess the knowledge, attitudes and practices of the communities on rabies. A cross-sectional study design and multistage sampling procedures were employed to select households for this study. Kebeles were randomly selected using lottery method from list of kebeles in each sub city, followed by selection of 42 households from each kebeles using systematic random sampling method. The data were collected from 1260 households through face to face interview using pre tested and structured questionnaires. Eighty three percent of the respondents indicated that they had previously heard about rabies. The majority of the study participants $932(75.2 \%)$ had moderate level of knowledge and those with satisfactory level of attitude were $649(52.3 \%)$ and with intermediate level of appropriate practices were $831(67.0 \%)$. There was strong association between knowledge scores and sex; educational level; occupation and household size $(p<0.05)$. However, statistically significant difference was observed only between attitude scores and: age, educational level and monthly income $(p<0.05)$. In this study, higher scores in practices to prevent rabies were recorded in male respondents those who completed higher education $(\mathrm{p}<0.05)$. Moreover, there was a strong positive correlation between knowledge and practice; attitude and practice. In this study a moderate level of awareness was shown with regard to rabies among the residents of Addis Ababa. Additionally, inaccessibility to appropriate services was also considered as a major reason for the low level of community participation in rabies prevention and control activities.

Key Words: Attitude, community, Knowledge, Practice, rabies http://dx.doi.org/10.4314/evj.v17i2.2 


\section{Introduction}

Rabies is a viral zoonosis, and human infection usually occurs following a transdermal bite or scratch by an infected animal (WHO, 1992). Globally, human mortality from endemic canine rabies was estimated to be 55,000 deaths per year and $56 \%$ of the estimated deaths occur in Asia and $44 \%$ in Africa (WHO, 2007). About 98\% of the human rabies cases occur in developing countries that possess large number of dogs, many of which are stray (WHO, 2004).

In Ethiopia, rabies is an important disease that has been recognized for many centuries (Mekonnen Fekadu, 1982). Nationwide data on rabies are not available to reveal the actual magnitude of the problem. However, the distribution of vaccine to the various regions and the fragmented reports on human and animal rabies cases are strong indicators of the wide spread nature of the disease in the country (Asefa Deressa et al., 2010). The magnitude of the problem is higher in big cities like Addis Ababa linked with the presence of large population of stray dogs and associated factors (Eshetu Yimer et al., 2002; Girma Tefera et al., 2002).

Different studies showed that rabies had been well established and become endemic in Addis Ababa (Girma Tefera et al, 2002; Paulos Abebe et al, 2003). It has been supported by high number of animal rabies confirmed cases in Addis Ababa during the past two decades and majority of rabies cases were confirmed in dogs. (Eshetu Yimer et al., 2002; Paulos Abebe et al., 2003; Bethlehem Newayeselassie et al., 2004; Abraham Ali et al., 2010;Asefa Deressa et al., 2010).

Poor public awareness towards rabies is considered as one of the bottle necks for the prevention and control of the disease in Ethiopia especially in canine rabies endemic cities like Addis Ababa. Understanding communities' perceptions of cause, mode of transmission, symptoms, treatment and possible intervention measures of rabies is an important step towards developing strategies aimed at controlling the disease and determining the level of implementation of planned activities in the future. Therefore, this study was designed to assess the level of knowledge, attitude and practices of selected communities in Addis Ababa on prevention and control of rabies. 


\section{Material and Methods}

Study Area and Population

This study was conducted in Addis Ababa during the months of January and February, 2011 to assess the knowledge, attitudes and practices of the communities on rabies. A cross-sectional study design and multi-stage sampling procedures were employed to select households for this study. Three kebeles (Lowest administrative structure) were randomly selected using lottery method from list of kebeles in each sub city, followed by selection of 42 households from each kebeles using systematic random sampling method. Whenever the selected household was found locked, the next household (on the right side) was substituted automatically for interview. The target population was household heads or their spouses who had lived in the area as permanent residents for more than six months.

\section{Sample Size}

The sample size was calculated using the formula for estimating single population proportion. The assumptions used were: a $95 \%$ confidence interval, a marginal error of 0.4 and the proportion of awareness level of $50 \%$. Ten percent non responsive rate and design effect of two were added and the required sample size of 1260 was computed.

\section{Data Collection}

Data was collected using pre-tested interviewer administered structured questionnaire. The questionnaire was developed based on the information gathered from literatures and on what the community is practicing. The questionnaire was first prepared in English and later translated to Amharic (National working language). Ten trained data collectors were recruited and trained to administer the questionnaires by moving house to house.

Data Analysis

The data from the questionnaires were entered into Epi-info 2008 version 3.5.1 software for data cleaning and were transferred to SPSS 12.0 for 
analysis. Scoring was done using the method described by Kaliyaperumal (2004). Descriptive, Chi-squire and linear correlation. Analyses were run using SPSS for windows version 12.0. Statistical significance was considered at $\mathrm{p}$ - value less than 0.05 .

\section{Ethical Considerations}

Ethical clearance and approval was obtained from University of Gondar and Addis Continental Institute of Public Health. Each participant was informed about the purpose of the study and informed consent was obtained from each respondent. Participation in the study was voluntary and respondents were free to withdraw from the study at any time. Interviews were anonymous and data remained confidential throughout the study.

\section{Results}

Socio-demographic characteristics

A total of 1260 household heads were interviewed during the study period. Of these the data collected from 20 respondents were found to be incomplete and excluded from the analysis. Only data from 1240 households were considered for the analysis. The age of the respondents ranged from 18 to 90 years, $63.9 \%$ were between the age of $18-49$ years and the majority of the respondents were female (55.6\%). Among the participants, $34.0 \%$ had completed secondary school and $10.3 \%$ had college undergraduate degrees whereas $12.8 \%$ of the participants were illiterate. Regarding religion, most of the respondents (75.1\%) were Orthodox Christians followed by Muslims (15.7\%). Some of the participants (29.8\%) were either government civil servants or employed by private companies and the rest $(11.1 \%)$ were engaged in running their own private businesses. About $27.3 \%$ of the respondents were housewives. Of the total, $41.9 \%$ earned less than 30 USD per month and few (7.4\%) earned more than 121 USD. For household size, more than half (53.5\%) of the respondents had family size between 3 and 6 . 
Knowledge, Attitude and Practice concerning Rabies

The levels of KAP concerning rabies are presented in Table 1. The data showed that $75.2 \%(95 \% \mathrm{CI}, 72.8-77.6 \%)$ of the respondents had moderate level of knowledge, with a range of 6.05-18.29 (mean $=12.17, \mathrm{SD}=6.12$ ). Regarding the attitude scores, $52.3 \%(95 \% \mathrm{CI}, 49.6-55.1 \%)$ respondents had intermediate attitude towards rabies ranged from 22.27 to 27.97 (mean = 25.12 , SD $=2.85)$. Similarly, $67.0 \%(95 \%$ CI, 64.4-69.6\%) of respondents were in the intermediate level of appropriate practices; ranging between 2.22 and $8.08($ mean $=5.15, \mathrm{SD}=2.93)$.

Table 1: Number and percent of respondents according to KAP levels of Rabies in Addis Ababa, January 2011

KAP levels

Knowledge score levels (25)

Low ( $<6.05$ scores)

Moderate (6.05-18.29 scores)

Good (>18.29 scores)

Attitudes score levels (28)

Low $(<22.27$ scores $)$

Moderate (22.27-27.97 scores)

Good (27.97 scores)

Practices score levels (13)

Low ( $<2.22$ scores)

Satisfactory (2.22-8.08 scores)

Good ( $>8.08$ scores)
Number

$\%(95 \% \mathrm{CI})$

29.1 (26.6-31.6)

649

52.3 (49.6-55.1)

230

$18.5(16.4-20.7)$

266

$21.5(19.2-23.7)$

831

$67.0(64.4-69.6)$

143

$11.5(9.8-13.33)$ 
Knowledge of rabies

This study revealed that almost all $(83.0 \%)$ study respondents had previously heard about rabies. Half of the respondents reported that informal/non mass media (family, teacher, traditional healer, professionals and friends) were the main sources of information for them about rabies. As shown in Figure 1, only $21.5 \%$ of the respondents received information about rabies from the formal/Mass media (Radio, Television, Magazine and Flayers).

Only small proportion of respondents (30.97\%) claimed to possess the basic knowledge of what rabies is and that it is a deadly disease. The vast majority of study participants (71.9\%), knew that it can affect all warm blooded animals including human beings and dogs are the major vector for rabies in Addis Ababa as reported by (73.5\%). Moreover, $81.5 \%$ of respondents recognize that it affects all human races regardless of the age.

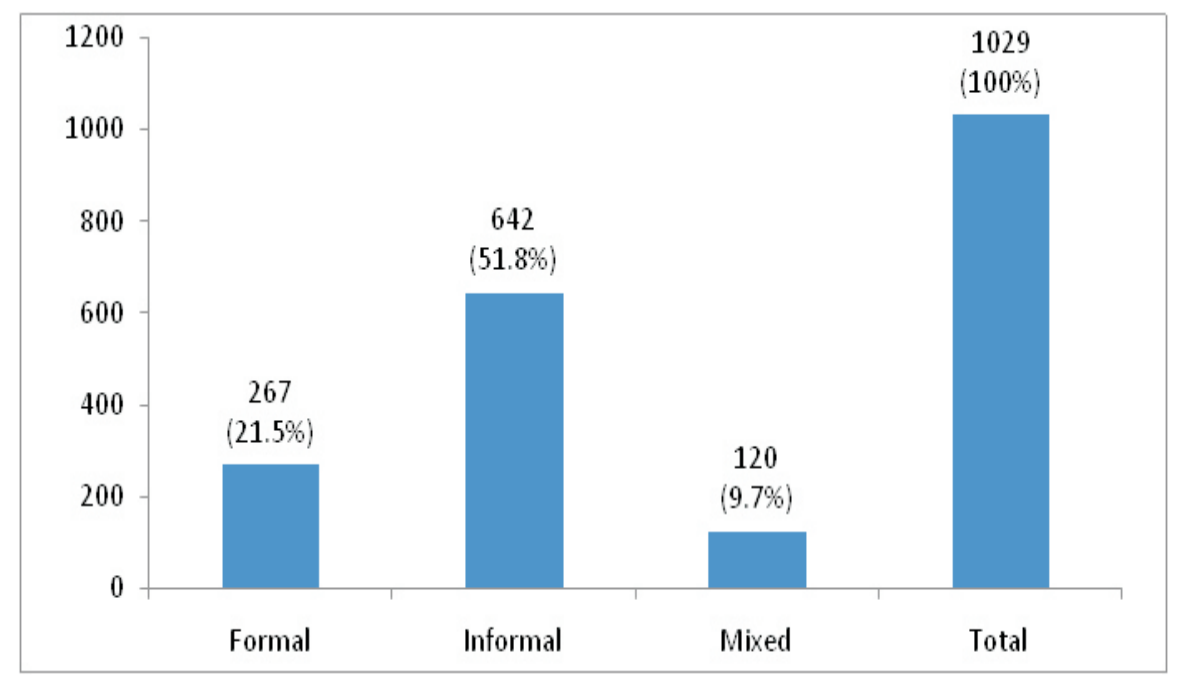

Figure 1: Frequencies and percentage of information sources on rabies, Addis Ababa, January 2011 
Only thirty four percent of the study respondents were able to identify most recognized clinical signs of the disease both in animals and human. However, It was widely perceived among respondents that bite was a main mode of rabies transmission from animal to animal $(67.8 \%)$, animal to human $(75.6 \%)$ and human to human $(42.4 \%)$. Majority of the respondents know that rabies can be prevented in animals $(46.6 \%)$ through regular vaccination against the disease. Only $28.7 \%$ of the respondents recognize the availability of rabies preventive measures in human and of these, $85.7 \%$ of them correctly answered that both immediate medical seek and taking post exposure treatment as effective preventive measures.

Association between independent variables and knowledge scores on rabies was calculated using Pearson's Chi square (Table 2). There was strong association between knowledge scores and $\operatorname{sex}(\chi 2=26.82, \mathrm{p}<0.001)$. The good scores were higher in males $(10.5 \%)$ than females $(5.08 \%)$. The majority of respondents of all groups had moderate level of knowledge. Educational level was significantly associated with knowledge scores $(\chi 2=$ 65.874, $\mathrm{p}<0.001)$. Respondents with higher education levels $(20.31 \%)$ had higher percentages of good rabies knowledge compared with those who had only finished primary school $(5.12 \%)$, high school $(7.82 \%)$, and had never attained school at all $(6.92 \%)$. Occupation had statistically significant association with knowledge levels $(\chi 2=40.971, \mathrm{p}<0.001)$. The highest knowledge levels were observed in employed/professionals $(9.89 \%)$ while the lowest was among unemployed/housewife (4.94\%). Moreover, statistically significant difference was observed among household size groups in the level of knowledge of respondents $(\chi 2=10.293, p=0.036)$. 
Table 2: Relationships between knowledge scores about rabies and some key independent variables among study respondents of Addis Ababa, January 2011.

\begin{tabular}{|c|c|c|c|c|c|c|}
\hline Variables & $\begin{array}{l}\text { Low } \\
\text { Number }(\%)\end{array}$ & $\begin{array}{l}\text { Moderate } \\
\text { Number }(\%)\end{array}$ & Good & $\chi^{2}$ & Df & $\mathrm{p}$ \\
\hline Sex & & & & 26.82 & 2 & 0.000 \\
\hline Male & $68(12.3)$ & $424(77.09)$ & $58(10.55)$ & & & \\
\hline Female & $147(21.30)$ & $508(73.62)$ & $35(5.08)$ & & & \\
\hline Age (Years) & & & & 8.639 & 4 & 0.071 \\
\hline $18-49$ & $155(19.57)$ & $583(73.61)$ & $154(6.82)$ & & & \\
\hline $50-64$ & $41(13.53)$ & $237(78.22)$ & $25(8.25)$ & & & \\
\hline$\geq 65$ & $19(13.10)$ & $112(77.24)$ & $14(9.66)$ & & & \\
\hline Educational Status & & & & 65.874 & 8 & 0.000 \\
\hline Primary & $67(19.03)$ & $\begin{array}{l}267(75.85) \\
336(79.62)\end{array}$ & $18(5.12)$ & & & \\
\hline $\begin{array}{l}\text { Secondary } \\
\text { Higher }\end{array}$ & $\begin{array}{l}53(12.56) \\
14(10.94)\end{array}$ & $\begin{array}{l}336(19.02) \\
88(68.75)\end{array}$ & $\begin{array}{l}35(1.82) \\
26(20.31)\end{array}$ & & & \\
\hline No formal Education & $33(18.44)$ & $141(78.77)$ & $5(2.79)$ & & & \\
\hline Illiterate & $48(30.19)$ & $100(62.89)$ & $11(6.92)$ & & & \\
\hline Religion & & & & 14.864 & 8 & 0.062 \\
\hline Orthodox Christian & $154(16.54)$ & $709(76.16)$ & $68(7.30)$ & & & \\
\hline Muslim & $43(22.05)$ & $142(72.82)$ & $10(5.13)$ & & & \\
\hline Protestant & $15(18.29)$ & $56(68.29)$ & $11(13.42)$ & & & \\
\hline Catholic & $3(12.00)$ & $20(80.00)$ & $2(8.00)$ & & & \\
\hline No religion & - & $5(71.43)$ & $2(28.57)$ & & & \\
\hline Occupation & & & & 40.971 & 8 & 0.000 \\
\hline Employed /Professional & $68(14.94)$ & $342(75.17)$ & $45(9.89)$ & & & \\
\hline Unemployed/Housewife & $106(24.94)$ & $298(70.12)$ & $21(4.94)$ & & & \\
\hline Unskilled worker & $17(20.48)$ & $60(72.29)$ & $6(7.23)$ & & & \\
\hline Pensioner & $12(8.63)$ & $119(85.61)$ & $8(5.76)$ & & & \\
\hline Private Business & $12(8.70)$ & $113(81.88)$ & $13(9.42)$ & & & \\
\hline Monthly income in USD & & & & 9.277 & 6 & 0.159 \\
\hline$<30$ & $98(18.88)$ & $386(74.38)$ & $35(6.74)$ & & & \\
\hline 31 to 60 & $78(17.73)$ & $333(75.68)$ & $29(6.59)$ & & & \\
\hline 61 to 120 & $29(15.34)$ & $138(73.02)$ & $22(11.64)$ & & & \\
\hline$>121$ & $10(10.87)$ & $75(81.52)$ & $7(7.61)$ & & & \\
\hline Household Size & & & & 10.293 & 4 & 0.036 \\
\hline $1-3$ & $62(23.13)$ & $185(69.03)$ & $21(7.84)$ & & & \\
\hline $4-6$ & $109(16.42)$ & $502(75.60)$ & $53(7.98)$ & & & \\
\hline$>6$ & $44(14.29)$ & $245(79.54)$ & $19(6.17)$ & & & \\
\hline Pet ownership & & & & 5.303 & 2 & 0.071 \\
\hline Yes & $1(0.32)$ & $276(87.62)$ & $38(12.06)$ & & & \\
\hline No & $4(0.56)$ & $656(91.75)$ & $55(7.69)$ & & & \\
\hline \multicolumn{7}{|l|}{ Source of Information } \\
\hline & & & & 9.171 & 4 & 0.057 \\
\hline Mass media & $2(0.7)$ & $251(94.0)$ & $14(5.2)$ & & & \\
\hline Non Mass media & $2(0.3)$ & $577(89.9)$ & $63(9.8)$ & & & \\
\hline Mixed Source & - & $104(86.7)$ & $16(13.3)$ & & & \\
\hline
\end{tabular}




\section{Attitude towards rabies}

More than $98 \%$ of the respondents were willing to vaccinate their pets, and almost all respondents $(98.2 \%)$ agreed to consult health professionals if they were bitten by dogs. However, 58.3\% the respondents had strong believe on traditional medicine for rabies prevention and treatment. Ninety-five percent of the respondents were in favor of implementing the mass vaccination program, and would want authorities to euthanize stray dogs for controlling rabies.

This study found that no statistical association exists between attitude scores and: statistically significant difference was observed between attitude scores and: age $(\chi 2=12.659, p=0.013)$, educational level $(\chi 2=74.947, p<0.001)$ and monthly income $(\chi 2=16.233, \mathrm{p}=.013)$. The relationship between attitude scores and selected independent variables are summarized in Table 3.

Table 3:Relationship between Attitude scores towards rabies and some key independent variables among study respondents of Addis Ababa, January 2011

\begin{tabular}{|c|c|c|c|c|c|c|}
\hline & Low & Moderate & Good & & & \\
\hline Variables & Number (\%) & Number $(\%)$ & Number (\%) & $\chi^{2}$ & Df & $\mathrm{p}$ \\
\hline$\overline{\text { Age (Years) }}$ & & & & 12.659 & 4 & 0.013 \\
\hline $18-49$ & $237(29.9)$ & $392(49.5)$ & $163(20.6)$ & & & \\
\hline $50-64$ & $75(24.8)$ & $180(59.4)$ & $48(15.8)$ & & & \\
\hline$\geq 65$ & $49(33.8)$ & $77(53.1)$ & $19(13.1)$ & & & \\
\hline Educational Status & & & & 74.947 & 8 & 0.000 \\
\hline Primary & $108(30.7)$ & $182(51.7)$ & $62(17.6)$ & & & \\
\hline Secondary & $97(23.0)$ & $227(53.8)$ & $98(23.2)$ & & & \\
\hline Higher & $21(16.4)$ & $74(57.8)$ & $33(25.8)$ & & & \\
\hline No formal Education & $53(29.6)$ & $92(51.4)$ & $34(19.0)$ & & & \\
\hline Illiterate & $82(51.6)$ & $74(46.5)$ & $3(1.9)$ & & & \\
\hline Religion & & & & 14.332 & 8 & 0.074 \\
\hline Orthodox Christian & $271(29.1)$ & $492(52.8)$ & $168(18.0)$ & & & \\
\hline Muslim & $64(32.8)$ & $93(47.7)$ & $38(19.5)$ & & & \\
\hline Protestant & $22(26.8)$ & $48(58.5)$ & $12(14.4)$ & & & \\
\hline Catholic & $4(16.00)$ & $11(44.00)$ & $10(40.00)$ & & & \\
\hline No re ligion & - & $5(71.4)$ & $2(28.6)$ & & & \\
\hline Monthly income in USD & & & & 16.233 & 6 & 0.013 \\
\hline$<30$ & $168(32.4)$ & $273(52.6)$ & $78(15.0)$ & & & \\
\hline 31 to 60 & $126(28.6)$ & $214(48.6)$ & $100(22.7)$ & & & \\
\hline 61 to 120 & $49(25.9)$ & $105(55.6)$ & $35(18.5)$ & & & \\
\hline$>121$ & $18(19.6)$ & $57(62.0)$ & $17(18.5)$ & & & \\
\hline Pet ownership & & & & 1.521 & 2 & 0.467 \\
\hline Yes & $51(16.2)$ & $190(60.3)$ & $74(23.5)$ & & & \\
\hline No & $100(14.0)$ & $459(64.2)$ & $156(21.8)$ & & & \\
\hline History of Animal bite & & & & 4.574 & 2 & 0.102 \\
\hline Yes & $15(15.0)$ & $71(71.0)$ & $14(14.0)$ & & & \\
\hline No & $135(14.5)$ & $578(62.2)$ & $216(23.3)$ & & & \\
\hline
\end{tabular}


Practice towards rabies preventive measures

Out of the 1240 respondents 314 had dogs, only 137 (43.6\%) vaccinate their pets against rabies and majority of dog owners (89.5\%) secured their pets by keeping them in cage or tied in the compound. Forty four per cent of the respondents did not vaccinate their dogs due to lack of knowledge on vaccine availability. As shown in Figure 2, the rest of the study participants who had pet but not get their pets vaccinated reported lack of attention, no nearby vet clinics, and expensive cost of the vaccine as main reasons.

Figure 2: Reasons reported by respondents for not vaccinating their pets, Addis Ababa, January 2011

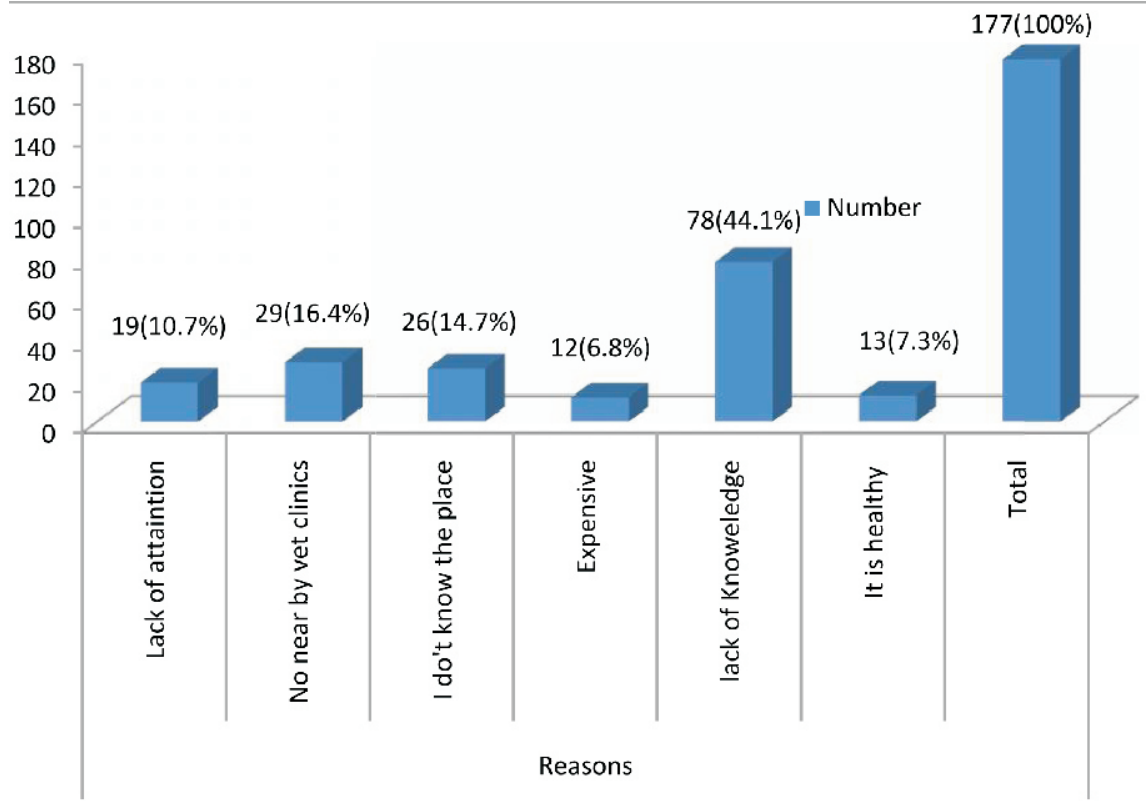

Practice scores were classified as "low", "satisfactory", and "good" (Table 4). This study revealed that males were more likely to have higher scores in practices to prevent rabies compared with females, although the difference was small $(\chi 2=10.829, \mathrm{p}=0.004)$. The respondents who completed higher level of education were more likely to have higher scores in practices to prevent rabies as compared with others $(\chi 2=43.968, \mathrm{p}<0.001)$. 


\section{KAP Correlation Analysis}

Linear Correlation analysis was done based on individual scores to determine the relationship between Knowledge, Attitude and Practice. There was strongly significant positive correlation between Knowledge and Attitude $(\mathrm{r}=0.888, \mathrm{p}<0.0001)$. Similarly, strongly significant positive correlation was recorded between Knowledge and Practice $(\mathrm{r}=0.706$, $\mathrm{p}<0.0001)$ and Attitude and Practice $(\mathrm{r}=0.775, \mathrm{p}<0.0001)$.

TABLE 4: Relationships between preventive practice scores and some key independent variables among study respondents of Addis Ababa, January 2011

\begin{tabular}{|c|c|c|c|c|c|c|}
\hline \multirow[b]{2}{*}{ Variables } & Low & Satisfactory & Good & \multirow[b]{2}{*}{$\chi^{2}$} & \multirow[b]{2}{*}{ Df } & \multirow[b]{2}{*}{$\mathrm{p}$} \\
\hline & Number (\%) & Number (\%) & Number (\%) & & & \\
\hline Sex & & & & 10.829 & 2 & 0.004 \\
\hline Male & $95(17.3)$ & $384(69.8)$ & $71(12.9)$ & & & \\
\hline Female & $171(24.8)$ & $447(64.8)$ & $72(10.4)$ & & & \\
\hline Age (Years) & & & & 12.659 & 4 & 0.366 \\
\hline $18-49$ & $180(22.7)$ & $526(66.4)$ & $86(10.9)$ & & & \\
\hline $50-64$ & $53(17.5)$ & $210(69.3)$ & $40(13.2)$ & & & \\
\hline$\geq 65$ & $33(22.8)$ & $95(65.5)$ & $17(11.7)$ & & & \\
\hline Educational Status & & & & 43.968 & 8 & 0.000 \\
\hline Primary & $80(22.7)$ & $233(66.2)$ & $39(11.1)$ & & & \\
\hline Secondary & $70(16.6)$ & $300(71.1)$ & $52(12.3)$ & & & \\
\hline Higher & $20(15.6)$ & $85(66.4)$ & $23(18.0)$ & & & \\
\hline No formal Education & $34(19.0)$ & $128(71.5)$ & $17(9.5)$ & & & \\
\hline Illiterate & $62(39.0)$ & $85(53.5)$ & $12(7.5)$ & & & \\
\hline Religion & & & & 20.944 & 8 & 0.007 \\
\hline Orthodox Christian & $198(21.3)$ & $612(65.7)$ & $121(13.0)$ & & & \\
\hline Muslim & $45(23.1)$ & $144(73.8)$ & $6(3.1)$ & & & \\
\hline Protestant & $19(23.2)$ & $51(62.2)$ & $12(14.6)$ & & & \\
\hline Catholic & $4(16.00)$ & $19(46.00)$ & $2(8.0)$ & & & \\
\hline No religion & - & $5(71.4)$ & $2(28.6)$ & & & \\
\hline Monthly income in USD & & & & 8.128 & 6 & 0.229 \\
\hline$<30$ & $123(23.7)$ & $344(66.3)$ & $52(10.0)$ & & & \\
\hline 31 to 60 & $95(21.6)$ & $287(65.2)$ & $58(13.2)$ & & & \\
\hline 61 to 120 & $36(19.0)$ & $131(69.3)$ & $22(11.6)$ & & & \\
\hline$>121$ & $12(13.0)$ & $69(75.0)$ & $11(12.0)$ & & & \\
\hline
\end{tabular}




\section{Discussion}

The findings of this study indicated that the majority of the respondents had moderate level of knowledge and attitude towards rabies and satisfactory level of rabies prevention practices. In contrast to this finding higher knowledge, more positive attitudes, and higher scores in practice indicators regarding rabies was reported from Sri Lanka (Gino et al., 2009). This difference probably is explained by the lack of health education programs about rabies in Ethiopia. Eighty-three percent of the respondents had heard about rabies from different sources. This finding was higher when compared with Ichhpujani et al ., (2006), that reported lower proportion $(68.7 \%)$ in a survey of knowledge, attitudes, and practices about animal bite and rabies in general community in India and in Zimbabwe, it was reported that $70 \%$ of the households were aware of rabies (Brooks,1990). Moderate level of knowledge score is observed although the majority of the study population had previously heard about rabies. This is mainly because of the fact associated with the source of information determining the appropriateness of the knowledge transferred. This is supported by the result obtained in this study that only $21.5 \%$ of respondents receive information about rabies from mass media in news or short spots. However, such information tended to be superficial, and it did not adequately enable public to acquire appropriate level of knowledge on rabies.

This KAP analysis revealed that only $30.97 \%$ of respondents recognize rabies as a fatal disease. Anita et al., (2003) reported that $38.88 \%$ of the study subjects were aware of the consequences of rabies following animal bite. Conversely, a study conducted in the city of New York, USA reported that $94.1 \%$ of the study participants know rabies as a killer disease (Eidson et al., 2004). However, in this study, majority of the respondents $(71.9 \%)$ know that rabies can affect all warm blooded animals and $73.5 \%$ of the respondents identified that dogs are major sources for the spread of rabies in human population. A study conducted in canine rabies endemic countries also testify similar results (Syed et al., 2009). 
In the present study, $75.5 \%$ of respondents knew that rabies to be transmitted through animal bite and only $42.4 \%$ knew that vaccination of animals could prevent rabies which is consistent with the finding of Lai et al., (2005), who reported that $61.1 \%$ and $49.2 \%$ answered correctly concerning transmission and prevention of rabies, respectively. However, the study conducted in Addis Ababa (Eshetu Yimer et al., 2012) among the community indicated that higher proportion of study participants (97.2\%) had correct responses regarding the route of exposure compared to the result found in this study which could be due to difference in study methodology.

The statistically significant difference $(\mathrm{P}<0.0001)$ in knowledge score between males and females might be due to increased activity of males in their daily life compared with females and better chance of acquiring correct information about rabies. Statistically significant association $(\mathrm{P}<0.0001)$ was observed between knowledge score and educational levels whereby higher levels of educations were associated with higher knowledge score.

The majority of the respondents indicated their willingness to vaccinate their pets and believe that mass vaccination program and depopulation of stray dogs are effective measures for controlling the disease in Addis Ababa. This finding was consistence with results recorded in Sir Lanka in which the majority of the participants were in favor of rabies control programs that mainly focused on stray dog population control (Gino et al., 2009). Lower proportions (54\%) of study subjects in favor of pets vaccination were also reported elsewhere (Lai et al., 2005). Almost all respondents agreed to consult health professional in case of animal bite. Similar proportion of respondents that sought medical care from a hospital or a doctor after being bitten by dogs was reported from Sri Lanka (Gino et al., 2009). In agreement with India's surveyed population where $42 \%$ preferred household treatment such as chili application (Agarwal and Reddaiah, 2003), 58.3\% participants of this study had strong belief on traditional medicine. The study also revealed statistically significant association between attitude scores and age, educational level and monthly income. The attitude score was found to increase with the age, educational level and monthly income. 
The level of Practice towards rabies preventive measures among the participant of this study was satisfactory. Almost all the pet owners keep their pets in secured cages or tied them in the compound. In contrast, a significant number of households in Sub-Saharan Africa were less likely to confine their dogs, whether in urban and rural areas (Butler and Bingham, 2000). Only, less than half of the pet owners had vaccinated their animals against rabies which is very low when it is compared with studies done in a community where the level of awareness is high and services delivery system is well established (Gino et al., 2009). The most common excuses that dog owners gave for a dog not vaccinated were lack of information about the importance of vaccine and inaccessibility of vaccination service. Brooks (1990) reported that the low level of practices regarding rabies

prevention and control in developing countries may reflect the inaccessibility of services that may enable the people to participate in rabies control programs. The practice score found in this study is associated with some of the sociodemographic characteristics. Hatch et al., (2004) reported similar significant association of rabies preventive practice and socioeconomic status of the respondent in Sierra Leone.

The Correlation analysis results showed that strong positive correlation; between Knowledge and Attitude, between Knowledge and Practice and Attitude and Practice scores. This suggests that good knowledge on rabies lead to good attitude and practice in prevention of rabies. Knowledge affects the individual's behavior and literatures on KAP studies revealed that healthy behaviors are enhanced by a person's increased level of knowledge (Ellen, 2009). Likewise, the individual practice towards the prevention of a disease is improved by promoting the attitude as attitude can impress all aspects of one's behavior (Ibrahim, 1995).

In conclusion, although the majority of the respondents have gained some knowledge about rabies from the informal sources, only small proportion of them possess the basic knowledge about the deadly nature of the disease. Since only $34 \%$ of the respondents were able to identify most recognized clinical signs of the disease both in animals and humans. The overall level of knowledge of the majority of the respondents was moderate that draws more 
attentions to be given for increasing the knowledge of the community about rabies. The majority of the study participants did not own dogs and only $43.6 \%$ of the respondents who own dogs get them vaccinated and keep them secured which is encouraging. However, lack of knowledge about the availability of vaccine and the prohibitive price when available was indicated as a main reason for the rest who do not get their dogs vaccinated. Therefore, information sources like radio, television programs and newspapers should play a significant role in enhancing the level of knowledge of the community about the deadly nature of rabies and the availability of preventive measures like vaccinations both for human and dogs.

\section{Acknowledgements}

The authors would like to thank households who participated in the study. We extend our gratitude to the data collectors and field supervisors.

\section{References}

Agarwal, N., Reddaiah, V. P., 2003. Knowledge, attitude and practice following dog bite: a community-based epidemiological study. Perspectives and Issues. 26:154-161.

Ali, A., Mengistu, F., Hussein, K., Getahun, G., Deressa, A., Yimer, E., and Tafesse, K., 2010. Overview of Rabies in and around Addis Ababa, in Animals Examined in EHNRI Zoonoses Laboratory Between, 2003 and 2009. Ethiop.Vet. J. 14 (2): 91-101.

Anita, K., Meena, D., and Malti, M., 2003. Profile of dog bite cases attending M.C.D. Dispensary at Alipur, Delhi. Indian Journal of community medicine, 28(4):1012.

Brooks, R., 1990. Survey of the dog population of Zimbabwe and its level of rabies vaccination. The Veterinary Record, 127:592-596.

Butler, R., and Bingham, J., 2000. Demography and human - dog relationships of the dog population in Zimbabwe communal lands. The Veterinary Record, 147:442446. 
Deresa, A., Ali, A., Beyene, M., Newayeselassie, B., Hussein, K., and Yimer, E., 2010.The status of Rabies in Ethiopia: A retrospective recored review. Ethiop.J. Hlth. Dev., 24(2), 127-132

Eidson, M., Kate, S., Mary, K., Charles, T., and Amy, W., 2004. Development and evaluation of bat rabies education materials. Evidence based preventive medicine, 1(2):85-91.

Ellen, V., 2009. Concepts and Challenges in the use of knowledge-attitude -practice surveys: Literature review. Department of Animal Health, Institute of Tropical Medicine, Antwerp, Belgium.

Fekadu, M., 1982. Rabies in Ethiopia. Amer.J.Epidmiol., 115 (2), 266-273.

Gino, C., Yoshihide O., Koji K., Hiroko, Y., Bandula, R., Gamini, P., et al., 2009. A pilot study on the usefulness of information and education campaign materials in enhancing the knowledge, attitude and practice on rabies in rural Sri Lanka. $J$ Infect Developing Countries 3(1), 55-64.

Hatch C., Sneddon J., and Jalloh G., 2004. A Descriptive study of urban rabies during the civil war in Sierra Leone: 1995-2001.Trop. Animal Hlth and Prod., 36(4), 321-334.

Ibrahim, G., 1995. Knowledge, attitude and practice the three pillars of excellence and wisdom: a place in the medical profession. Eastern Mediterranean Health Journal., 1(1):8-16.

Ichhupujani, R., Chhabra, M., Mittal V., Bhattacharya D., Lal S., 2006. Knowledge, Attitude and Practices about animal bites and rabies in general community -a multi-centric study. Journal of communicable Disease, 38(4), 355-361.

Kaliyaperumal, K., 2004. Guideline for Conducting a Knowledge, Attitude and Practice (KAP) Study. AECS Illumination, 4(1), 7-9.

Lai, P., Rawat, A., Sagar, A., and Tiwari, K., 2005. Prevalence of Dog bite in Delhi: Knowledge and Practices of residents regarding prevention and control of rabies. Health and Population perspectives and Issues. 28(2):50-57.

Syed, F., Munazza, J., Shanila, N., Sumaira, A., Faisal, S., Sana, et al., 2009. Knowledge and Practices among the general practitioners of Karachi regarding dog bite management. Journal of Pakistan medical Association, 59:861-864. 
Tefera, G., Yimer, E., and Geyid, A., 2002. Endemic existence of rabies in Ethiopia. Ethiop. Med.J., 40, 163-170.

WHO, 1992. Eighth report of the WHO Expert committee on rabies: Technical report series No.79. Geneva, Switzerland.

WHO, 2004. First Report of Expert the WHO Consultation on Rabies: Technical Report Series 931. Geneva, Switzerland.

WHO, 2007. WHO recommendations on rabies post-exposure treatment and the correct technique of intradermal immunization against rabies: Geneva, Switzerland.

Yimer, E., Mesfin, A., Beyene, M., Bekele, A., Taye, G., Zewdie, B., and Alemayehu, T., 2012. Study on knowledge, attitude and dog ownership patterns related to rabies prevention and control in Addis Ababa, Ethiopia. Ethiop. Vet. J., 2012, 16(2), 27-39

Yimer, E., Newayeselassie, B., Tefera, T., Mekonnen, Y., Bogale, Y., Zewdie, B., Beyene, M., and Bekele, A., 2002. Situation of Rabies in Ethiopia: A retrospective study 1990-2000. Ethiop. J. Hlth Dev., 16(1), 105-112. 